\section{Data-sharing for indigenous peoples}

Broad-consent models for human studies, which leave decisions on data-sharing to the researchers, may not be appropriate for work with indigenous peoples. Making the sharing of data almost impossible is also problematic. Everyone stands to benefit from responsible data-sharing innovations that can be applied more widely.

The largest volume of genomic data amassed so far from Aboriginal Australians is deposited in the European Genome-phenome Archive (A.-S. Malaspinas et al. Nature 538, 207-214; 2016). The Australian board for ethical review permits access to the data only for "verification" purposes, and subject to ethical approval. For any other use of the data, researchers must seek permission from the original researchers, obtain ethical approval and contact the donors individually for their re-consent. This becomes prohibitive because donors are spread all over the continent.

These hurdles may be intended to protect participants from the harms of data-sharing, but they also exclude them from the potential benefits. Other models better address the foundational principles of responsible sharing, as proposed by the Global Alliance for Genomics and Health (B. M. Knoppers HUGO J. 8, $3 ; 2014)$, and the control of research by indigenous study participants. The National Centre for Indigenous Genomics (see go.nature. com/2slp6q6) in Canberra, for example, combines indigenous governance with dynamic consent that allows project participants to opt in or out of having their data shared (J. Kaye et al. Eur. J. Hum. Genet. 23, 141-146; 2015).

Emma Kowal Deakin University, Melbourne, Australia.

\section{Bastien Llamas University of Adelaide, Australia. Sarah Tishkoff University of \\ Fight fake reagents with digital tools} Pennsylvania, Philadelphia, USA. emma.kowal@deakin.edu.au

\section{Religion's openness towards science}

Your Editorial suggests that Pope Francis's meeting with patients and researchers is evidence of "a new openness [of religion] towards science", in the spirit of his 2015 encyclical Laudato si' (Nature 545, 265-266; 2017). This is tempered by your view that the encyclical nevertheless illustrates "a chasm between religion and science that cannot be bridged".

In my view, the encyclical's most fruitful comment on science and religion is that they have "distinctive approaches to understanding reality" (paragraph 62; see go.nature. $\mathrm{com} / 2 \mathrm{swk} 22 \mathrm{~m}$ ). The essence of this distinctiveness is that the modern scientific approach never invokes God as an explanation for any phenomenon. This restatement of 'methodological naturalism' is not science being anti-God: it is science being science. All scientists adhere to this approach, including scientists who believe in God. In the religious approach, by contrast, God is at the heart of phenomena.

It follows that the fundamental distinction between science and religion has nothing to do with the question of whether or not God exists.

These insights can inform the debate around what should and should not be taught in science classes on, for example, evolution. In shedding light on the nature of the "chasm" between science and religion, these insights can also inform the new openness to which you refer.

Frank W. Nicholas University of Sydney, Australia.

frank.nicholas@sydney.edu.au
Digital technologies are emerging that could be used to stop the burgeoning market in fake research reagents that are contaminating global biomedical supply chains (see Nature 545, 148-150;2017).

The international counterfeitdrugs market is even more lucrative. Estimates of its worth ranged from US $\$ 75$ billion to $\$ 200$ billion last year, and it accounts for half of all medicines sold in some lowincome countries (see go.nature. com/2rjwvya). This causes health problems and even death for millions of people (see go.nature.com/2s5ojzi).

Promising digital tools such as radio frequency identification (RFID) and blockchain technology can help to combat this counterfeit trading (see T. K. Mackey and G. Nayyar Exp. Opin. Drug Safety 16, 587-602; 2017). By using radio frequencies that uniquely identify an object, animal or person, RFID is highly efficient at tracking and tracing. Blockchain digitizes supply chains, enabling online verification of genuine items and protection against fakes (see also G. Chapron Nature 545, 403-405; 2017).

Strong governance across countries is needed to create the regulatory and legal frameworks necessary to incorporate such technologies into public policy. Don Gunasekera Deakin University, Melbourne, Australia. don.gunasekera@deakin.edu.au

\section{Document India's floral biodiversity}

This month's bicentenary of the birth of Joseph Dalton Hooker, one of the great botanical explorers of the nineteenth century, is a good time to highlight the urgent need to document India’s remarkable biodiversity for conservation purposes (see also J. Endersby
Nature 546, 472-473; 2017). Hooker's compilation, The Flora of British India (1872-97), was the first, and is still the most authoritative, account of flowering plants in the country, which at that time included present-day Pakistan, Bangladesh and parts of Myanmar. Hooker corresponded with Charles Darwin on the 100 species of Himalayan Impatiens (balsams) he found (see go.nature.com/2sdxeby), new species of which are being discovered even now.

In his 1855 book Himalayan Journals, Hooker remarked on the vast stretches of dense forest in Darjeeling and Sikkim. Expanding populations, infrastructure development and climate change have since reduced these to a patchwork of fragments.

Botanists in India today are equipped with digital tools and facilities for fieldwork undreamed of by Hooker. Time is running out for them to produce a complete and authenticated list of the country's plants and to document plant-associated ecosystem services for the benefit of India's people and the world. Kamaljit S. Bawa University of Massachusetts, Boston, USA. R. Ganesan Ashoka Trust for Research in Ecology and the Environment, Bangalore, India. kamal.bawa@gmail.com

\section{CONTRIBUTIONS}

Correspondence may be sent to correspondence@nature. com after consulting the author guidelines at http://go.nature. com/cmchno.

\section{CORRECTION}

The Spotlight article 'The genetic microscope' (Nature 545, S25-S27; 2017) said that Orit Rozenblatt-Rosen was an associate director at the Klarman Cell Observatory. In fact, she is the scientific director there. 


\section{CORRECTION}

The Correspondence by E. Kowal et al. (Nature 546, 474; 2017)

wrongly located the University of

Pennsylvania in Pittsburgh instead of Philadelphia. 